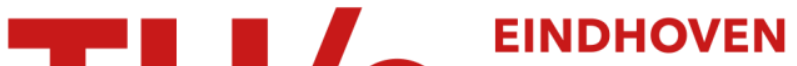

\section{Halbach permanent magnet shape selection for slotless tubular actuators}

Citation for published version (APA):

Meessen, K. J., Gysen, B. L. J., Paulides, J. J. H., \& Lomonova, E. A. (2008). Halbach permanent magnet shape selection for slotless tubular actuators. IEEE Transactions on Magnetics, 44(11), 4305-4308.

https://doi.org/10.1109/TMAG.2008.2001536

DOI:

10.1109/TMAG.2008.2001536

Document status and date:

Published: 01/01/2008

\section{Document Version:}

Publisher's PDF, also known as Version of Record (includes final page, issue and volume numbers)

\section{Please check the document version of this publication:}

- A submitted manuscript is the version of the article upon submission and before peer-review. There can be important differences between the submitted version and the official published version of record. People interested in the research are advised to contact the author for the final version of the publication, or visit the $\mathrm{DOI}$ to the publisher's website.

- The final author version and the galley proof are versions of the publication after peer review.

- The final published version features the final layout of the paper including the volume, issue and page numbers.

Link to publication

\section{General rights}

Copyright and moral rights for the publications made accessible in the public portal are retained by the authors and/or other copyright owners and it is a condition of accessing publications that users recognise and abide by the legal requirements associated with these rights.

- Users may download and print one copy of any publication from the public portal for the purpose of private study or research.

- You may not further distribute the material or use it for any profit-making activity or commercial gain

- You may freely distribute the URL identifying the publication in the public portal.

If the publication is distributed under the terms of Article $25 \mathrm{fa}$ of the Dutch Copyright Act, indicated by the "Taverne" license above, please follow below link for the End User Agreement:

www.tue.nl/taverne

Take down policy

If you believe that this document breaches copyright please contact us at:

openaccess@tue.nl

providing details and we will investigate your claim. 


\title{
Halbach Permanent Magnet Shape Selection for Slotless Tubular Actuators
}

\author{
Koen J. Meessen, Bart L. J. Gysen, Johannes J. H. Paulides, and Elena A. Lomonova \\ Electromechanics and Power Electronics, Eindhoven University of Technology, Eindhoven, The Netherlands
}

\begin{abstract}
This paper describes the effects of changing the magnet shape of permanent magnets (PMs) in a Halbach array applied in a slotless tubular actuator. More specifically, the square shaped magnets are replaced by trapezoidal shaped magnets. A semi-analytical magnetic field solution of regular square shaped magnets is presented and used to approximate the airgap field produced by the trapezoidal shaped PMs. The method is based on dividing the magnets into several radial layers and superposition of the fields to calculate the total magnetic field. The results are compared to finite element analysis (FEA) and show excellent agreement. Using this magnetic field solution, the effect of the shape of the magnets on the magnetic field waveform is analyzed by means of a parametric search.
\end{abstract}

Index Terms-Halbach, magnetic field, permanent-magnet machines.

\section{INTRODUCTION}

$\mathbf{T}$ HIS paper describes the merits of changing the permanent magnet (PM) shape in Halbach arrays, when applied to tubular actuators. These actuators are increasingly used due to their high efficiency, high power/force density, and excellent servo characteristics [1]. In this respect, it has been shown that slotless tubular PM actuators using quasi-Halbach magnetization patterns have a number of attractive characteristics, such as a sinusoidal back-electromotive force (back-EMF) waveform, which result in a very low electromagnetic force ripple and the possibility of being optimized to achieve almost zero cogging force [2]-[4]. A further advantage is that quasi-Halbach magnetized magnets are virtually "self-shielding," and therefore, the magnetic flux which passes through the core is relatively weak. Hence, in this paper a nonmagnetic core is considered. A major advantage of using non-magnetic material, e.g., aluminium or air, is the mass reduction, which is particularly interesting for high acceleration applications.

In most publications a quasi-Halbach magnet array with square magnets is used, however, [5] presents the results of a double-sided PM linear motor with trapezoidal shaped permanent magnets. The Halbach PM array with trapezoidal shaped magnets is illustrated in Fig. 1(b). The force of the actuator is slightly increased compared to conventional quasi-Halbach magnetization. This paper will describe the semi-analytical means to enhance the airgap field by varying the permanent magnet shape in tubular actuators. As such, Section II presents the semi-analytical modeling of the quasi-Halbach topology with square magnets. Section III presents the modified model to include the changing magnet shape, where Section IV shows the effect of varying the magnet shape on the magnetic field distribution in the airgap/coil region.

\section{Semi-Analytical Model}

To develop a fast and accurate analysis tool, a semi-analytical model is derived for the calculation of the magnetic field produced by the permanent magnets. Several papers have been

Digital Object Identifier 10.1109/TMAG.2008.2001536

Color versions of one or more of the figures in this paper are available online at http://ieeexplore.ieee.org. (a)

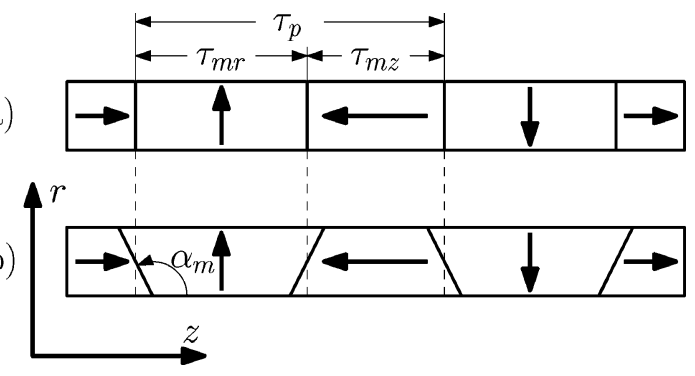

Fig. 1. Quasi-Halbach magnetization pattern. (a) Regular square permanent magnets. (b) Trapezoidal shaped permanent magnets.

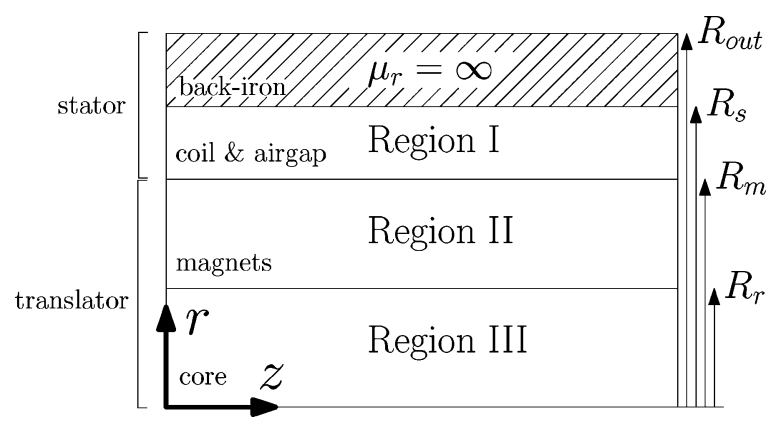

Fig. 2. Model of a slotless tubular permanent magnet actuator considering different regions.

written on the subject of field calculations by semi-analytical modeling. In [6], [7], semi-analytical solutions for the magnetic fields due to a quasi-Halbach magnet array in tubular actuators are presented. The papers describe a model for a regular square shaped quasi-Halbach magnet array. This paper investigates the effects of changing the regular square shape into a trapezoidal shape.

In order to obtain the solution of the semi-analytical fieldequations, the tubular actuator is divided in several regions as shown in Fig. 2. In this model, the following assumptions are made:

1) the soft-magnetic parts are infinitely permeable;

2) the actuator is infinitely long, hence, end-effects are neglected;

3) the permanent magnets have a linear demagnetization characteristic, and are fully and homogeneously magnetized in the direction of magnetization. 
The semi-analytical description of the actuator is obtained by solving the magneto-static field equations using the vector potential, $\vec{A}$, defined as

$$
\vec{B}=\nabla \times \vec{A}
$$

where $\vec{B}$ is the magnetic flux density [8]. Due to the symmetry in the circumferential direction in tubular actuators, the magnetic flux density, $\vec{B}$, has only an $r$ - and a $z$-component. Therefore, the magnetic vector potential has only a circumferential, $\theta$-component, hence can be treated as a scalar potential. The two components of the magnetic field as function of $A_{\theta}$ are

$$
\begin{aligned}
& B_{r}=-\frac{\partial}{\partial z} A_{\theta} \\
& B_{z}=\frac{\partial}{r \partial r} r A_{\theta} .
\end{aligned}
$$

As only the magnetic field due to the permanent magnets in the actuator is calculated here, with no current in the windings, the magnetic vector potential has to be solved in two different regions. The regions are shown in Fig. 2, where regions I and III are source-free regions in which the Laplace equation has to be solved

$$
\nabla^{2} \vec{A}_{\mathrm{I}, \mathrm{III}}=0
$$

and in the magnet, region II, the Poisson equation has to be solved

$$
\nabla^{2} \vec{A}_{\mathrm{II}}=-\mu_{0} \nabla \times \vec{M} .
$$

In this, $\vec{M}$ is the magnetization vector describing the magnet array on the translator by a Fourier series

$$
\begin{aligned}
\vec{M} & =M_{r} \vec{r}+M_{z} \vec{z} \\
& =\sum_{n=1}^{\infty} M_{r n} \sin \left(m_{n} z\right) \vec{r}+\sum_{n=1}^{\infty} M_{z n} \cos \left(m_{n} z\right) \vec{z} \\
M_{r n} & =\frac{4 B_{r e m}}{\mu_{0} \tau_{p} m_{n}} \sin \left(\frac{m_{n} \tau_{p}}{2}\right) \sin \left(\frac{m_{n} \tau_{p} \alpha_{p}}{2}\right) \\
M_{z n} & =\frac{4 B_{r e m}}{\mu_{0} \tau_{p} m_{n}} \sin \left(\frac{m_{n}\left(1-\alpha_{p}\right) \tau_{p}}{2}\right)
\end{aligned}
$$

where $m_{n}$ is the spatial frequency which contains only odd harmonics

$$
m_{n}=\frac{(2 n-1) \pi}{\tau_{p}},
$$

$\mu_{0}$ is the permeability of vacuum, $\tau_{p}$ is the pole pitch, and $\alpha_{p}$ is the ratio between the radially magnetized magnet pitch and the pole pitch as shown in Fig. 1. Solving the Laplace equation, (4), and the Poisson equation, (5), results in a vector potential with a Bessel distribution in the $\vec{r}$-direction and a sinusoidal distribution in the $\vec{z}$-direction. Using the relations (2) and (3), the magnetic flux density, $\vec{B}$, in the different regions is

$$
\begin{aligned}
B_{\mathrm{I} r} & =\sum_{n=1}^{\infty}\left(a_{1 n} \mathcal{B}_{\mathcal{I} 1}\left(m_{n} r\right)+b_{1 n} \mathcal{B}_{\mathcal{K} 1}\left(m_{n} r\right)\right) \sin \left(m_{n} z\right) \\
B_{\mathrm{I} z} & =\sum_{n=1}^{\infty}\left(a_{1 n} \mathcal{B}_{\mathcal{I} 0}\left(m_{n} r\right)-b_{1 n} \mathcal{B}_{\mathcal{K} 0}\left(m_{n} r\right)\right) \cos \left(m_{n} z\right)
\end{aligned}
$$

$$
\begin{aligned}
B_{\mathrm{II} r}= & \sum_{n=1}^{\infty}\left[\left(\mathcal{K}_{a n}\left(m_{n} r\right)+a_{2 n}\right) \mathcal{B}_{\mathcal{I} 1}\left(m_{n} r\right)\right. \\
& \left.-\left(\mathcal{K}_{b n}\left(m_{n} r\right)-b_{2 n}\right) \mathcal{B}_{\mathcal{K} 1}\left(m_{n} r\right)\right] \sin \left(m_{n} z\right) \\
B_{\mathrm{II} z}= & \sum_{n=1}^{\infty}\left[\left(\mathcal{K}_{a n}\left(m_{n} r\right)+a_{2 n}\right) \mathcal{B}_{\mathcal{I} 0}\left(m_{n} r\right)\right. \\
& \left.+\left(\mathcal{K}_{b n}\left(m_{n} r\right)-b_{2 n}\right) \mathcal{B}_{\mathcal{K} 0}\left(m_{n} r\right)\right] \cos \left(m_{n} z\right) \\
B_{\mathrm{III} r}= & \sum_{n=1}^{\infty}\left(a_{3 n} \mathcal{B}_{\mathcal{I} 1}\left(m_{n} r\right)+b_{3 n} \mathcal{B}_{\mathcal{K} 1}\left(m_{n} r\right)\right) \sin \left(m_{n} z\right) \\
B_{\mathrm{IIIz}}= & \sum_{n=1}^{\infty}\left(a_{3 n} \mathcal{B}_{\mathcal{I} 0}\left(m_{n} r\right)-b_{3 n} \mathcal{B}_{\mathcal{K}_{0}}\left(m_{n} r\right)\right) \cos \left(m_{n} z\right)
\end{aligned}
$$

where $\mathcal{B}_{\mathcal{I} i}(r)$ and $\mathcal{B}_{\mathcal{K} i}(r)$ are modified Bessel functions of the first and second kind, respectively, with order $i$, $a_{1 n}, b_{1 n}, a_{2 n}, b_{2 n}, a_{3 n}, b_{3 n}$ are coefficients derived from the boundary conditions and given in the appendices together with the functions $\mathcal{K}_{a n}$ and $\mathcal{K}_{b n}$. The coefficients $a_{1 n}$ to $b_{3 n}$ are found by considering periodicity in the axial direction and by applying the boundary conditions

$$
\begin{aligned}
\left.B_{\mathrm{I} z}(r, z)\right|_{r=R_{s}} & =0 \\
\left.A_{\mathrm{III} \theta}(r, z)\right|_{r=0} & =0 \\
\left.B_{\mathrm{I} r}(r, z)\right|_{r=R_{m}} & =\left.B_{\mathrm{II} r}(r, z)\right|_{r=R_{m}} \\
\left.B_{\mathrm{II} r}(r, z)\right|_{r=R_{r}} & =\left.B_{\mathrm{III} r}(r, z)\right|_{r=R_{r}} \\
\left.H_{\mathrm{I} z}(r, z)\right|_{r=R_{m}} & =\left.H_{\mathrm{II} z}(r, z)\right|_{r=R_{m}} \\
\left.H_{\mathrm{II} z}(r, z)\right|_{r=R_{r}} & =\left.H_{\mathrm{III} z}(r, z)\right|_{r=R_{r}} .
\end{aligned}
$$

These boundary conditions result in a matrix with equations which is presented in the Appendix. In [9], a design optimization for a slotted tubular machine is presented. However, the design is optimized for the highest force in a slotted machine, therefore a new parametric search is performed to achieve a sinusoidal flux density in a slotless machine.

\section{TRAPEZOIDAL MAGNETS}

In the previous section, a semi-analytical model for a quasiHalbach topology with square magnets is derived. In this section, this model is extended to be able to investigate the influence of the angle $\alpha_{m}$ of the trapezoidal magnet on the flux density as shown in Fig. 1.

As the magnetization vector of a trapezoidal Halbach magnet array is a function of both radius and axial position, the solution of the Poisson equation, (5), becomes more complex if not impossible to solve. Therefore, the solution of the field is approximated by splitting the magnet region into $J$ layers as shown in Fig. 3. As the model in the previous section is linear, i.e. soft-magnetic parts are assumed to be infinitely permeable, it is valid to use superposition. Therefore, the total field distribution in the airgap can be obtained by summation of the the magnetic field due to each permanent magnet layer. An additional assumption is the relative permeability of unity for the magnets. Consider, for example layer 2, the field of this layer is obtained by modeling a magnet with parameters $R_{r, 2}>R_{r}, R_{m, 2}<$ $R_{m}$, and $\alpha_{p, 2}$. Region I comprises now $R_{m, 2}<r<R_{s}$, which implies that for the calculation of the field due to layer 2 , the layers $2<j<J$ are modeled as vacuum with a relative perme- 


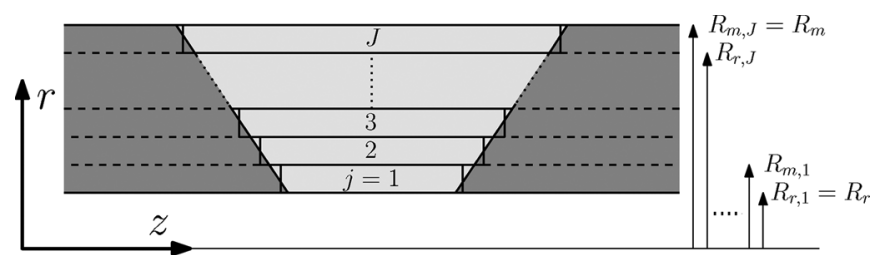

Fig. 3. Model of the trapezoidal magnetization, where the magnet region is split into $J$ layers.

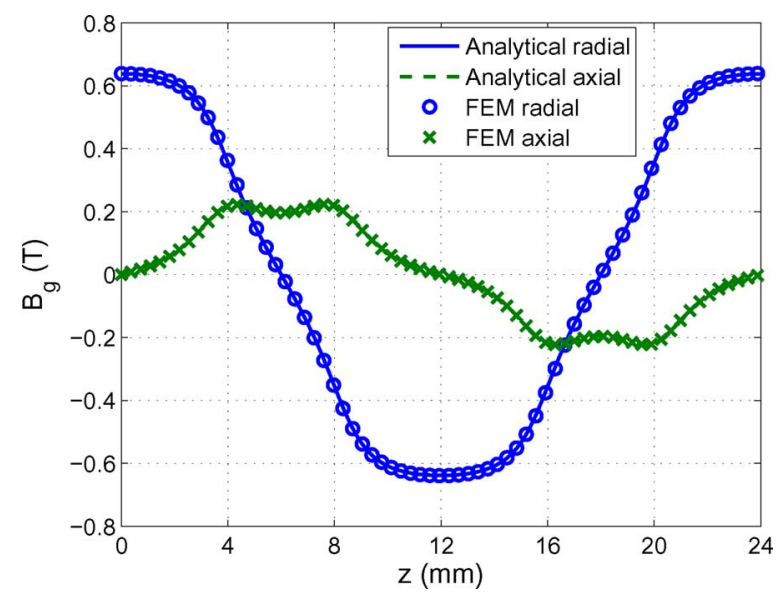

Fig. 4. Comparison of the radial and axial component of the flux density calculated by semi-analytical means and FEA for $\alpha_{m}=120^{\circ}$ in the center of region II. The semi-analytical field solution is calculated for $J=6$.

TABLE I

PARAMETERS OF THE MODELED ACTUATOR

\begin{tabular}{|c|c|c|}
\hline$R_{s}(\mathrm{~mm})$ & 25.0 & Inner stator radius \\
\hline$R_{m}(\mathrm{~mm})$ & 22.5 & Outer magnet radius \\
\hline$R_{r}(\mathrm{~mm})$ & 17.5 & Inner magnet radius \\
\hline$\tau_{p}(\mathrm{~mm})$ & 12.0 & Pole pitch \\
\hline$\alpha_{p}$ & 0.45 & Radial magnet pitch to pole pitch ratio \\
\hline$B_{r e m}(\mathrm{~T})$ & 1.2 & Remanent flux density PM \\
\hline$\mu_{r}$ & 1.05 & Relative permeability PM \\
\hline
\end{tabular}

ability of one. The same holds for region III, layer 1 is modeled as vacuum as this region includes now $0<r<R_{r, 2}$.

The results of the above described model are compared to a finite element analysis (FEA) to verify the approach. The permanent magnets in the FE model have a remanent flux density, $B_{\text {rem }}$, of $1.2 \mathrm{~T}$ and a relative permeability, $\mu_{r}$, of 1.05 . As can be seen in Fig. 4, the results show excellent agreement for a number of layers, $J$ equals 6 .

\section{RESULTS}

To evaluate the effect of changing the magnet shape, the field distribution in the center of region I is calculated for several values of $\alpha_{m}$. First, the model is optimized using a parametric search to maximize the first harmonic of the flux density of the slotless square quasi-Halbach topology, consequently, the found parameters are used to investigate the effect of changing $\alpha_{m}$. The parameters are summarized in Table I. Fig. 5 shows the resulting waveform for three different values of $\alpha_{m}$ where

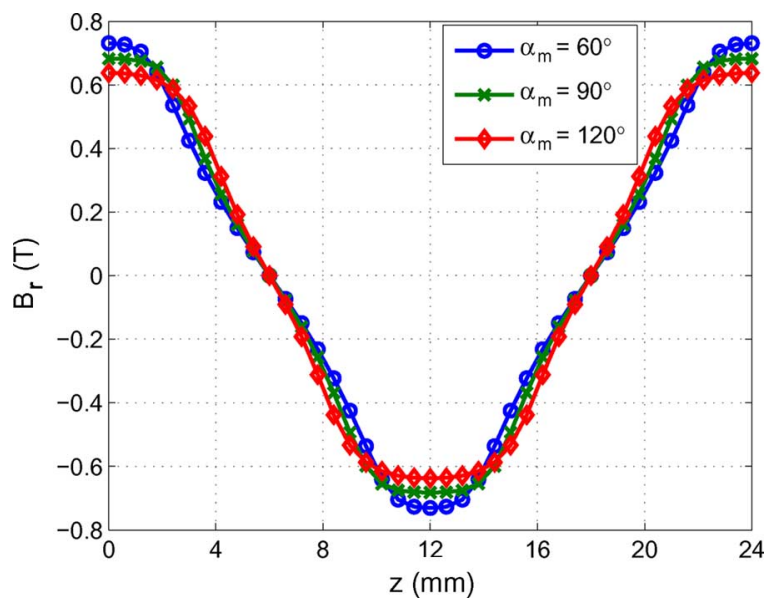

Fig. 5. Effect of $\alpha_{m}$ on the waveform of the radial component of the flux density in the center of region II.

$\alpha_{m}=90^{\circ}$ corresponds to a square quasi-Halbach magnetization. As shown in the figure, the peak value of the waveform for $\alpha_{m}=60^{\circ}$ is higher. However, when the rms value and the value of the first harmonic are taken into account, the influence of $\alpha_{m}$ is much smaller.

From the parametric search follows that the effect of $\alpha_{m}$ on the flux density distribution is independent of the radial length of region I. Increasing the radial magnet length intensifies the influence of $\alpha_{m}$ on the flux density. The relation between $\alpha_{m}$ and the flux density is shown for constant actuator dimensions. As can be seen from the results shown in Fig. 6, the optima for the rms value and the peak value of the first harmonic are very close to $90^{\circ}$ or conventional Halbach with square magnets. However, the peak value and the total harmonic distortion $\left(\mathrm{THD}_{B}\right)$ show different optima, where

$$
\operatorname{THD}_{B}=\frac{\sqrt{\sum_{n=2}^{\infty} \hat{B}_{n}^{2}}}{\hat{B}_{1}}
$$

Thus the parameter $\alpha_{m}$ can be used to decrease the $\mathrm{THD}_{B}$ or to increase the peak value of the flux density. However, a more evident parameter to achieve this behavior is the ratio $\alpha_{p}$. Using this parameter, the $\mathrm{THD}_{B}$ and the peak flux density can be adjusted as well, a comparison is presented in Table II.

\section{CONCLUSIONS}

A parametric search on the magnet shape in a quasi-Halbach magnet array in a slotless tubular actuator, showed a relative small influence of the trapezoidal magnet shape $\left(\alpha_{m}\right)$ on the flux density in region I. As such, the rms and fundamental value of the flux density are constant while the peak value varies $10 \%$ when $\alpha_{m}$ is changed from $60^{\circ}$ to $120^{\circ}$. However, a similar result can be achieved by adjusting the ratio between the axially and radially magnetized magnets, $\alpha_{p}$.

To conclude, the results presented in this paper are valid for slotless tubular PM actuators. An additional analysis was undertaken to which extend the magnet shape would affect the airgap flux density in a slotted tubular PM actuator. Therefore, the radial length of region I, which comprises the coil and the airgap, is reduced to $0.5 \mathrm{~mm}$. The analysis shows an increase of the peak 


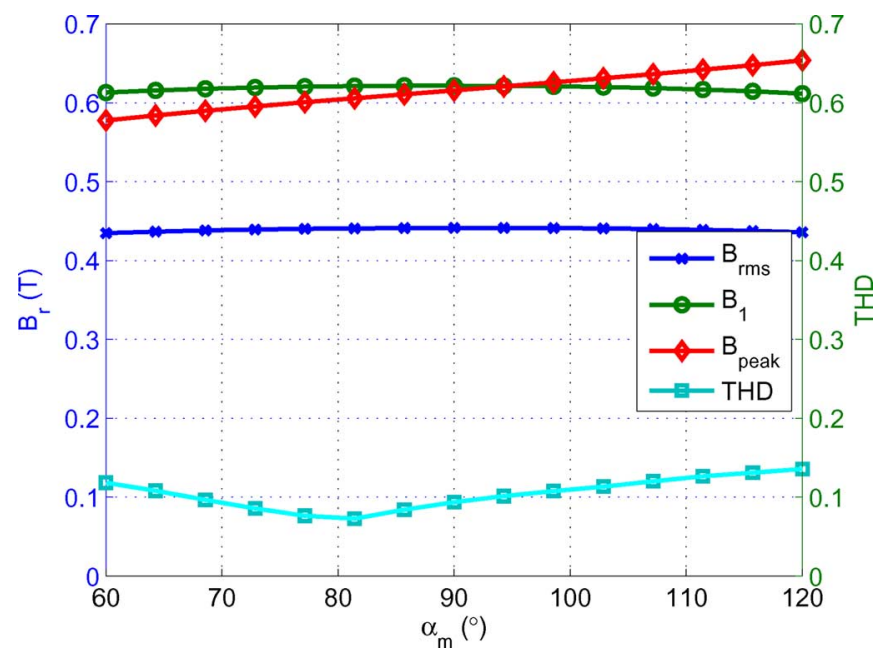

Fig. 6. The effect of $\alpha_{m}$ on the rms value, $B_{r m s}$, the first harmonic, $B_{1}$, the peak value, $B_{\text {peak }}$, and the total harmonic distortion (THD) of the flux density in the center of region II.

TABLE II

COMPARISON BETWEEN VARYING $\alpha_{m}$ AND $\alpha_{p}$

\begin{tabular}{|c|c|c|c|c|}
\hline & $\mathrm{B}_{r m s}(\mathrm{~T})$ & $\mathrm{B}_{I}(\mathrm{~T})$ & $\mathrm{B}_{\text {peak }}(\mathrm{T})$ & $\mathrm{THD}_{B}$ \\
\hline$\alpha_{m}=60^{\circ}$ & 0.487 & 0.682 & 0.731 & 0.16 \\
\hline$\alpha_{p}=0.36$ & 0.490 & 0.685 & 0.733 & 0.18 \\
\hline$\alpha_{m}=120^{\circ}$ & 0.485 & 0.684 & 0.638 & 0.15 \\
\hline$\alpha_{p=0.54}$ & 0.488 & 0.688 & 0.631 & 0.12 \\
\hline
\end{tabular}

value of the airgap flux density by $45 \%$ when varying $\alpha_{m}$ between $60^{\circ}$ and $120^{\circ}$, which can not be achieved by varying $\alpha_{p}$. However, additional research using the method presented in this paper is necessary as the desired flux density waveform strongly depends on the actuator topology.

\section{APPENDIX}

First define the following diagonal matrices

$$
\begin{array}{ll}
\mathbf{C}_{1 N}=\operatorname{diag}\left(\mathcal{B}_{\mathcal{I} 0}\left(m_{n} R_{r}\right)\right), & \mathbf{C}_{2 N}=\operatorname{diag}\left(\mathcal{B}_{\mathcal{K}_{0}}\left(m_{n} R_{r}\right)\right), \\
\mathbf{C}_{3 N}=\operatorname{diag}\left(\mathcal{B}_{\mathcal{I} 1}\left(m_{n} R_{r}\right)\right), & \mathbf{C}_{4 N}=\operatorname{diag}\left(\mathcal{B}_{\mathcal{K}_{1}}\left(m_{n} R_{r}\right)\right), \\
\mathbf{C}_{5 N}=\operatorname{diag}\left(\mathcal{B}_{\mathcal{I} 0}\left(m_{n} R_{m}\right)\right), & \mathbf{C}_{6 N}=\operatorname{diag}\left(\mathcal{B}_{\mathcal{K}_{0}}\left(m_{n} R_{m}\right)\right), \\
\mathbf{C}_{7 N}=\operatorname{diag}\left(\mathcal{B}_{\mathcal{I} 1}\left(m_{n} R_{m}\right)\right), & \mathbf{C}_{8 N}=\operatorname{diag}\left(\mathcal{B}_{\mathcal{K}_{1}}\left(m_{n} R_{m}\right)\right), \\
\mathbf{C}_{9 N}=\operatorname{diag}\left(\mathcal{B}_{\mathcal{I} 0}\left(m_{n} R_{s}\right)\right), & \mathbf{C}_{10 N}=\operatorname{diag}\left(\mathcal{B}_{\mathcal{K}_{0}}\left(m_{n} R_{s}\right)\right) .
\end{array}
$$

Further, define the following functions

$$
\begin{aligned}
& \mathcal{K}_{a n}\left(m_{n} r\right)=-\mu_{0} M_{r n} \int_{m_{n} R_{r}}^{m_{n} r} \mathcal{B}_{\mathcal{K} 1}(x) x d x \\
& \mathcal{K}_{b n}\left(m_{n} r\right)=-\mu_{0} M_{r n} \int_{m_{n} R_{r}}^{m_{n} r} \mathcal{B}_{\mathcal{I} 1}(x) x d x .
\end{aligned}
$$

The boundary conditions result in a set of linear equations which can be written in matrix form as

$$
\left[\begin{array}{c}
\mathbf{a}_{1 N} \\
\mathbf{b}_{1 N} \\
\mathbf{a}_{2 N} \\
\mathbf{b}_{2 N} \\
\mathbf{a}_{3 N}
\end{array}\right]=\mathbf{E}^{-1} \mathbf{Y}
$$

where $\mathbf{a}_{1 N}, \mathbf{b}_{1 N}, \mathbf{a}_{2 N}, \mathbf{b}_{2 N}$ and $\mathbf{a}_{3 N}$ are column vectors with elements $a_{1 n}, b_{1 n}, a_{2 n}, b_{2 n}$ and $a_{3 n}$, respectively. Finally, $\mathbf{E}$ and $\mathbf{Y}$ are given by

$$
\begin{aligned}
& \mathbf{E}=\left[\begin{array}{ccccc}
\mathbf{C}_{9 N} & -\mathbf{C}_{10 N} & \mathbf{0} & \mathbf{0} & \mathbf{0} \\
\mathbf{0} & \mathbf{0} & \mathbf{C}_{1 N} & -\mathbf{C}_{2 N} & -\mu_{r} \mathbf{C}_{1 N} \\
\mathbf{C}_{7 N} & \mathbf{C}_{8 N} & -\mathbf{C}_{7 N} & -\mathbf{C}_{8 N} & \mathbf{0} \\
\mu_{r} \mathbf{C}_{5 N} & -\mu_{r} \mathbf{C}_{6 N} & -\mathbf{C}_{5 N} & \mathbf{C}_{6 N} & \mathbf{0} \\
\mathbf{0} & \mathbf{0} & \mathbf{C}_{3 N} & \mathbf{C}_{4 N} & -\mathbf{C}_{3 N}
\end{array}\right] \\
& \mathbf{Y}=\left[\begin{array}{c}
\mathbf{0} \\
\mu_{0} \mathbf{M}_{z N} \\
\mathbf{C}_{7 N} \mathcal{K}_{a N}-\mathbf{C}_{8 N} \mathcal{K}_{b N} \\
\mathbf{C}_{5 N} \mathcal{K}_{a N}+\mathbf{C}_{6 N} \mathcal{K}_{b N}-\mu_{0} \mathbf{M}_{z N} \\
\mathbf{0}
\end{array}\right]
\end{aligned}
$$

where $\mathbf{M}_{z N}, K_{a N}$ and $\boldsymbol{K}_{b N}$ are $\mathrm{N} \times 1$ matrices with elements $M_{z n}, \mathcal{K}_{a n}$ and $\mathcal{K}_{b n}$, respectively.

\section{REFERENCES}

[1] J. F. Eastham, "Novel synchronous machines: Linear and disc," Electr. Power Applicat., IEE Proc. B, vol. 137, pp. 49-58, Jan. 1990.

[2] J. Wang, D. Howe, and G. W. Jewell, "Fringing in tubular permanentmagnet machines: Part II. cogging force and its minimization," IEEE Trans. Magn., vol. 39, no. 6, pp. 3517-3522, Nov. 2003.

[3] K. Halbach, "Design of permanent multipole magnets with oriented rare earth cobalt material," Nucl. Instrum. Methods, vol. 69, no. 1, pp. $1-10,1980$.

[4] J. Mallinson, "One-sided fluxes-A magnetic curiosity?," IEEE Trans. Magn., vol. 9, no. 4, pp. 678-682, Dec. 1973.

[5] M. G. Lee and D. G. Gweon, "Optimal design of a double-sided linear motor with a multi-segmented trapezoidal magnet array for a high precision positioning system," J. Magn. Magn. Mater., vol. 271, pp. 336-346, Jun. 2004.

[6] J. Wang, G. W. Jewell, and D. Howe, "A general framework for the analysis and design of tubular linear permanent magnet machines," IEEE Trans. Magn., vol. 35, no. 3, pp. 1986-2000, May 1999.

[7] J. Wang and D. Howe, "Tubular modular permanent-magnet machines equipped with quasi-halbach magnetized magnets-Part I: Magnetic field distribution, EMF, and thrust force," IEEE Trans. Magn., vol. 41, no. 9, pp. 2470-2478, Sep. 2005.

[8] E. P. Furlani, Permanent Magnet and Electromechanical Devices. New York: Academic, 2001.

[9] J. Wang and D. Howe, "Tubular modular permanent-magnet machines equipped with quasi-Halbach magnetized magnets-Part II: Armature reaction and design optimization," IEEE Trans. Magn., vol. 41, no. 9, pp. 2479-2489, Sep. 2005.

Manuscript received March 03, 2008. Current version published December 17, 2008. Corresponding author: J. J. H. Paulides (e-mail: J.J.H.paulides@ @ue. $\mathrm{nl})$. 